\title{
Representações sociais de cuidadores principais de pacientes com demência
}

\author{
Social representations of main caretakers of patients with dementia
}

\author{
Daniela Chiari Rizzo', Virgínia Torres Schall ${ }^{2}$ \\ ${ }^{1}$ Mestranda, Instituto de Pesquisa René Rachou, Fundação Oswaldo Cruz (FIOCRUZ), Rio de Janeiro, RJ. Médica psiquiatra, Prefeitura de Belo \\ Horizonte, Belo Horizonte, MG. ${ }^{2}$ Doutorado em Educação, Pontifícia Universidade Católica do Rio de Janeiro (PUCRJ), Rio de Janeiro, RJ. \\ Pesquisadora titular, Instituto Pesquisa René Rachou, FIOCRUZ. \\ O presente estudo foi realizado no Laboratório de Educação em Saúde, Instituto René Rachou, Fundação Oswaldo Cruz (FIOCRUZ), Rio de Janeiro, \\ RJ. Baseado em dissertação de mestrado, com o mesmo título do artigo, a ser defendida no Instituto Pesquisa René Rachou, FIOCRUZ, \\ provavelmente no início de novembro de 2007.
}

\section{Resumo}

Introdução: As síndromes depressivas e demenciais são os problemas mentais mais prevalentes na população idosa. A qualidade de vida de pacientes com demência depende, primordialmente, daqueles que são responsáveis pelos seus cuidados. Assim, é fundamental a realização de estudos que possam descrever as percepções, interpretações e reações dos cuidadores frente aos diversos tipos de síndromes demenciais, as estratégias encontradas para enfrentá-las associadas aos diferentes atores e a mobilização de referentes culturais em torno da experiência da demência.

Método: No presente estudo, com base na teoria das representações sociais, foram entrevistados 15 cuidadores, visando compreender como estes reconhecem e vivenciam a síndrome demencial e quais são as ações realizadas por eles para lidar com a mesma.

Resultados: A análise de conteúdo indicou que o prejuízo nas atividades instrumentais foram os primeiros sinais que alertaram os cuidadores para o problema de seus familiares. Ao mesmo tempo em que os cuidadores consideram eventos de vida, organicidade e hereditariedade para explicar o problema do familiar, levantam também outros aspectos que estão intimamente associados ao contexto sociocultural, influenciando as ações diante das manifestações da síndrome demencial.

Conclusão: Essas são informações essenciais para o planejamento de intervenções e políticas públicas adequadas às características dessa população.

Descritores: Cuidadores, demência, representações sociais, envelhecimento.

\begin{abstract}
Introduction: Depressive symptoms and dementia are the most prevalent mental problems among the elderly. The quality of life of patients suffering from these disorders depends mostly on their caretakers. Therefore, it is of paramount importance to conduct research studies describing the caretaker's perceptions, interpretations and actions in relation to different types of dementia disorders, coping strategies developed associated with different actors and mobilization of cultural references connected to the experience of dementia.

Method: In the present study, based on the theory of social representations, 15 caretakers were interviewed, focusing on their experiences and feelings about this disorder and their coping strategies.

Results: Content analysis indicated that decreased instrumental activities were the first signs alerting caretakers about their relative's problem. At the same time as caretakers consider life events, organicity and heredity to explain their relative's problem, they also raise other aspects, which are intimately associated with the sociocultural context, influencing the actions taken regarding the dementia syndrome.

Conclusion: This is essential information to plan interventions and public policies adapted to the characteristics of that population. Keywords: Caretaker, dementia, social representation, ageing.
\end{abstract}




\section{Introdução}

O envelhecimento populacional é um fenômeno demográfico mundial que levou a uma mudança na estrutura etária da população, com aumento do peso relativo das pessoas acima de 60 anos. Como conseqüência da queda de fecundidade, o processo de envelhecimento populacional brasileiro tem se acentuado. Isso pode ser exemplificado por um aumento da população idosa no total da população nacional. Até a década de 1960, a população do Brasil era extremamente jovem, em torno de $52 \%$ abaixo de 20 anos e menos de $3 \%$ acima dos 65 anos. A proporção de habitantes com 60 anos de idade ou mais dobrou entre 1950 e 1991 (de 3,5 para 7,3\%), e a proporção daqueles com 65 anos ou mais quase triplicou no mesmo período (1,7 para 4,6\%) (Instituto Brasileiro de Geografia e Estatística, Censos Demográficos 1950-1991). Não só o grupo de idosos tem crescido mais do que outros grupos populacionais, como entre os idosos observa-se um aumento do número e da proporção dos muito idosos, com mais de 80 anos $^{1}$.

Os idosos apresentam mais problemas de saúde que a população geral. Quando se fala sobre as doenças presentes na terceira idade, é importante lembrar a parcela que cabe aos transtornos mentais. As síndromes depressivas e demenciais são os problemas mentais mais prevalentes na população idosa. A demência pode ser definida como uma síndrome caracterizada por declínio da memória, associado a déficit de pelo menos uma outra função cognitiva (linguagem, gnosias, praxias ou funções executivas), com intensidade suficiente para interferir no desempenho social ou profissional do indivíduo, na ausência de comprometimento agudo do estado de consciência ${ }^{2}$.

A prevalência de demência duplica a cada 5 anos após os 60 anos, resultando em um aumento exponencial com a idade ${ }^{3}$. Uma revisão de estudos de prevalência mostra taxas médias que variaram de $0,7 \%$, na faixa etária de $60-64$ anos, a $38,6 \%$, na faixa de 90-95 anos ${ }^{4}$. No Brasil, existem poucos estudos de prevalência de demência. Um estudo de base populacional realizado na cidade de Catanduva (SP) avaliou 1.660 pessoas com 60 anos ou mais e detectou prevalências variando de $1,3 \%$, na faixa etária de 65-69 anos, a 36,9\%, para a faixa etária de 85 anos ou mais ${ }^{5}$.

Como a demência é um quadro crônico e progressivo, chega um momento no qual o cuidado domiciliar do paciente pode gerar intensa sobrecarga para os cuidadores ${ }^{6}$. Por "cuidador", entende-se o indivíduo responsável por prover ou coordenar os recursos requeridos pelo paciente ${ }^{7}$. Aproximadamente
$80 \%$ dos cuidadores de um paciente com demência são membros da família que cuidam desses indivíduos em casa ${ }^{8}$. Levesque et al. ${ }^{9}$ destaca que o suporte social formal e informal protege o bem-estar psicológico dos membros da família que cuidam do paciente. $\mathrm{O}$ cuidado formal, organizado e eficiente a idosos dependentes praticamente não existe no Brasil, sendo a família a responsável por esse cuidado ${ }^{10}$.

Os aspectos socioculturais do envelhecimento estão se tornando mais centrais aos cuidados e tratamento bem-sucedidos de pessoas idosas. As escolhas atuais de tratamento de indivíduos com demência favorecem os cuidados na comunidade e na própria casa do indivíduo, contextos nos quais a própria cultura pode ser mais abertamente expressa do que em contextos de cuidados institucionais. Elementos como a família, as relações sociais, a cultura e os serviços de saúde têm um impacto na maneira como a experiência da demência é vivenciada $^{11}$. Na família, os mecanismos utilizados para adaptação à nova situação são bastante variados e podem influenciar a consciência da doença. Outra influência importante é o tipo de conhecimento sobre o diagnóstico e a dificuldade em compartilhar o que está ocorrendo ${ }^{12}$. No ambiente doméstico, os grupos sociais colocam em prática uma variedade de conhecimentos, crenças, valores e atitudes que circundam o processo de saúde, doença e cuidado ${ }^{13}$. Por isso, é interessante analisar como as famílias cuidadoras descrevem e interpretam a doença e como essas representações afetam as relações familiares, as práticas de cuidado e a busca por tratamentos de saúde.

Assim, no presente estudo, fundamentado na teoria das representações sociais, buscou-se compreender o modo como os familiares do paciente com demência reconhecem e vivenciam a síndrome demencial e quais são as ações realizadas por eles para lidar com essa síndrome. Essas são informações essenciais para o planejamento de políticas adequadas às características da população-alvo.

\section{Método}

O referencial teórico-metodológico que orientou este trabalho é o das representações sociais entendidas como modalidades de conhecimento prático orientadas para a comunicação e para a compreensão do contexto social, material e ideativo. São formas de conhecimento que se manifestam como elementos cognitivos - imagens, conceitos, categorias, teorias -, mas que não se reduzem jamais aos componentes cognitivos ${ }^{14,15}$. As representações sociais são socialmente elaboradas 
e compartilhadas, contribuindo para a construção de uma realidade comum, que possibilita a comunicação.

Para a realização deste estudo, foram selecionados cuidadores de pacientes com demência moradores de Belo Horizonte (MG). Todos foram selecionados através da indicação de geriatras e psiquiatras de serviços de saúde públicos (centros de saúde Dom Cabral e São Jorge, vinculados à prefeitura de Belo Horizonte), conveniados (ambulatório de psiquiatra e psicologia do Hospital Militar e ambulatório de geriatria do Departamento de Estradas e Rodagens) e particulares que acompanham os respectivos indivíduos com a síndrome demencial. Para a inclusão de sujeitos no grupo, era necessário indicar o familiar que fosse o responsável principal pelo cuidado ao paciente e que esse último tivesse o diagnóstico clínico de demência (apenas as mais comuns: Alzheimer, vascular, corpos de Lewy, frontotemporal e Parkinson) dentro de definições atualizadas da nosologia, associado ou não a exames de neuroimagem.

Para reconstruir o universo de representações associado à síndrome demencial apresentada por idosos, optou-se por uma abordagem qualitativa. Utilizou-se um roteiro semi-estruturado para as entrevistas, elaborado com o intuito de investigar as maneiras de pensar e agir relativas à demência, assim como identificar o reconhecimento do problema e a atitude para lidar com ele. Foram investigados as manifestações e os problemas associados aos sintomas/sinais da demência, o universo de representações e de comportamentos. O critério de saturação foi utilizado para estabelecer o número de entrevistas, tendo sido suficientes 15 para alcançar os requisitos estabelecidos. Para identificar as variáveis sociodemográficas, o instrumento utilizado foi o questionário sociodemográfico baseado em Oliveira \& Oliveira ${ }^{16}$, construído com o intuito de averiguar a estrutura etária populacional, a renda, o gênero, o estado civil e a inserção profissional.

Para trabalhar os dados obtidos na investigação qualitativa, optou-se pela técnica de análise de conteúdo ${ }^{17}$. Essa busca compreender o sentido da comunicação e, principalmente, desviar o olhar para outra significação, outra mensagem através ou ao lado da mensagem primeira ${ }^{17}$.

A análise dos dados foi realizada em duas etapas. Na primeira etapa, os dados provenientes de cada entrevistado foram analisados separadamente. Após a transcrição e informatização de todas as entrevistas, os textos foram analisados em função de categorias identificadas nos esquemas de codificação. Esses esquemas de codificação foram construídos em função de leitura sistemática do conjunto de entrevistas. A partir daí, as categorias de informação recorrentes foram identificadas.

Treze cuidadores preferiram ser entrevistados em suas casas, sendo que alguns justificaram essa preferência pela necessidade de ficarem próximos aos pacientes para auxiliá-los se necessário e por não terem com quem deixá-los. Somente dois preferiram ser entrevistados nos serviços de saúde onde seus familiares fazem acompanhamento, considerando a privacidade e a proximidade desses locais.

Com a aprovação pelo comitê de ética do projeto de pesquisa, a pesquisadora apresentava-se como pesquisadora do Instituto de Pesquisa René Rachou, Fundação Oswaldo Cruz, explicava o estudo, solicitava a assinatura do termo de consentimento e permissão para gravar a entrevista. Procurava sempre estabelecer um diálogo para deixar o entrevistado à vontade e seguia o fluxo da conversa até abranger todos os itens do roteiro semi-estruturado. As entrevistas gravadas foram posteriormente transcritas. O tempo de duração das entrevistas variou entre 40 minutos e 1 hora e 30 minutos. Os nomes citados após os fragmentos de falas dos entrevistados (nos resultados e discussão) são fictícios.

\section{Resultados e discussão}

\section{Características dos cuidadores}

Os 15 entrevistados têm idades que variam entre 34 e 83 anos, sendo 14 do sexo feminino e um do sexo masculino. Quanto ao grau de parentesco, nove são filhas, duas são sobrinhas e uma é irmã do paciente, sendo que uma das sobrinhas, na verdade, não é parenta consangüínea. Três são esposos dos pacientes. Cinco cuidadoras trabalham fora e têm renda própria, que varia entre três e 10 salários mínimos. Elas atuam e acumulam as funções do trabalho fora de casa aos cuidados dos pacientes na própria residência. Oito cuidadoras não trabalham fora, sendo que uma delas recebe um salário mínimo para cuidar do familiar, proveniente da renda do próprio paciente. Dois são aposentados e têm renda que varia entre cinco e 20 salários mínimos. A renda familiar varia entre três e 23 salários mínimos. Quanto à escolaridade, três cuidadoras têm o ensino fundamental incompleto, e duas completaram o ensino fundamental. Outras quatro têm o ensino médio completo, e seis têm nível universitário. $\mathrm{O}$ tempo durante o qual estão cuidando do familiar varia entre 4 meses e 23 anos, sendo que cinco já cuidam de seus familiares há pelo menos 10 anos, e nove, entre 2 e 5 anos. 


\section{Apresentação e interpretação das categorias}

Após leitura flutuante do conjunto das comunicações, foram identificadas sete categorias e 20 subcategorias que comandaram a especificação dos temas. Após discussão entre as duas participantes da pesquisa (aluna e orientadora), essas categorias e subcategorias foram organizadas em cinco grandes eixos temáticos, de forma a orientar o tratamento dos resultados obtidos e a interpretação: primeiros sinais que alertaram o cuidador sobre a existência de um problema com o familiar; interpretações de origem sociocultural, histórica e/ou biológica para as alterações do familiar; reações do cuidador às alterações do familiar; dificuldades enfrentadas pelo cuidador para o cuidado do familiar; relações do cuidador com os profissionais de saúde.

Para a realização desse artigo, foram selecionados os três primeiros eixos referentes às percepções, interpretações e reações dos entrevistados diante das alterações apresentadas pelos respectivos familiares. Esses três temas contribuem para uma melhor compreensão do universo das representações sobre a demência por parte dos cuidadores e suas conseqüências quanto ao tratamento e ações de cuidado.

\section{Primeiros sinais que alertaram o cuidador sobre a existência de um problema com o familiar}

Esse eixo temático surgiu a partir da questão do roteiro semi-estruturado: "Como percebeu que seu familiar estava com o problema?". Para responder a essa pergunta, os entrevistados descreveram um ou mais dos sinais citados a seguir.

Em suas narrativas, três cuidadores reconhecem o declínio da memória, que é um requisito primário para o diagnóstico da demência (“... ela está um pouquinho esquecida, às vezes, ela perde muito documento, ela esquece onde está e fica revirando tudo" - Lídia), e quatro, a desorientação (“... ele ia na padaria... passava um pouquinho, mamãe ligava e falava: 'seu pai não voltou'. Então, a gente saía pelo bairro e logo achava, às vezes passava uns apertos, aconteceu isso umas cinco vezes. Uma vez, ele foi parar quase indo pra Sabará..." - Célia) como os primeiros sinais que os alertaram para o problema de seus familiares. Três reconhecem manifestações de alteração cognitiva na capacidade de comunicação ("A família começou a perceber que ela começou a não falar coisa com coisa, às vezes ela não assimila o que a gente está falando, e aí que a gente começou a perceber" - Joana) e uma cuidadora identifica o não-reconhecimento de pessoas já conhecidas (agnosia) como indicativos de uma alteração no paciente (“... ele começou a esquecer os nomes dos netos, dos filhos. A gente falava: 'pai, é a M'. Aí, ele falava: 'quem é M.?'. Aí, tinha que falar: 'é a sua neta'. Nós fomos observando que tinha alguma coisa..." - Célia).

As alucinações visuais ("ela começou... a ver uma coisa que não era. Por exemplo, uma vez tinha um araticum... na fruteira, ela me chamou bem baixinho: 'vem cá, tem um urutu enroladinho na fruteira'. Um urutu, era uma cobra, aí eu falei assim, 'não, mãe, isso não é urutu não, isso é um araticum"” - Clarice) foram, para dois cuidadores, e as alterações de humor (“... ela estava gostando muito de ficar deitada na cama, triste, o que não era o jeito dela..." - Luíza), para três, os primeiros sinais da síndrome demencial. Embora a citação acima que exemplifica as alucinações visuais seja, provavelmente, um exemplo de parafasia, a entrevistada percebeu essa manifestação como importante na identificação de um problema, por considerá-la uma alucinação.

Todos os cuidadores descrevem sintomas comportamentais surgidos ao longo do processo de cuidado. As alterações de comportamento que mais foram citadas pelos cuidadores são: maneirismos repetitivos (no caso, o ato de varrer "sem parar, compulsivamente"), fuga, agitação e agressividade verbal e/ou física. Uma entrevistada deu-se conta da possibilidade de uma doença acometendo o familiar após observar alterações em seu comportamento, o qual se tornava progressivamente mais agressivo. $\mathrm{O}$ fato de a paciente em questão ter sido considerada sempre "muito nervosa" parece ter contribuído para retardar a percepção de seu adoecimento, devido à associação dos sinais iniciais da demência com seu temperamento forte (“... a gente sempre a vê agressiva, nervosa, que toda vida ela foi muito nervosa... é assim que a gente começou a perceber... ficou aquela nervosa assim diferente... que ela ficava nervosa, falava, falava e pronto, mas depois ela começou a ficar diferente, a querer me agredir" Clara).

As manifestações de progressivo comprometimento das atividades da vida diária instrumentais, como habilidade para lidar com dinheiro e pagar contas, fazer compras e executar trabalhos de rotina (por exemplo, cozinhar, lavar, costurar), foram as mais freqüentemente descritas como alertas para um problema no familiar, sendo comentadas por sete cuidadores.

Primeiro sintoma foi deixar de fazer as coisas que ela costumeiramente fazia muito bem... Por exemplo, ela começava a lavar as vasilhas e parava, 
ela começava a sentar na máquina de costurar e levantava... ela saía e demorava muito e perdia o que ia fazer. Por exemplo, ela gostava de costurar, ela era costureira, se ela saía para buscar uma linha, ela chegava sem a linha, ou, por exemplo, chegava com o fecho ou com nada ou perdia o dinheiro... (Maria)

No final do ano, me chamou muito a atenção porque ele recebeu o $13^{\circ}$ salário, quase 6 mil reais no dia 15 de dezembro. Quando chegou no dia 3 de janeiro, só tinha 70 reais e não sabia o que tinha feito com o dinheiro... e todas as contas atrasadas, não tinha pagado nada, ai eu pensei que tinha alguma coisa errada... (Hilda)

Os primeiros sinais que alertaram esses cuidadores têm pertinência para o estudo em questão, pois permitem avaliar o estágio da doença - no caso da demência de Alzheimer (DA) - em que os cuidadores se dão conta de que algum problema está acometendo o seu familiar. Para a maior parte dos entrevistados que cuidam de pacientes com DA, os sinais que chamaram a atenção para esse problema foram compatíveis com os encontrados na fase intermediária da doença, na qual houve iniciativa de buscar a ajuda médica. A demência começa com sintomas de memória muito leves, que, em geral, não são percebidos ou considerados pelos cuidadores como motivos para preocupação quanto à saúde do familiar ("Porque eram coisas pequenininhas, não era nada que, digamos assim, estivesse atrapalhando nem ela e nem a vida das pessoas que estavam ao redor, eram coisas sutis" - Lídia). É comum que o diagnóstico seja realizado após 3 anos de evolução da doença, período em que o tratamento com medicamentos poderia ser mais eficaz ${ }^{18}$. Somente três cuidadoras - sendo que duas são filhas, com nível universitário, e uma é esposa, com ensino médio completo - perceberam prejuízos mais leves da memória que são compatíveis com a fase leve da doença. As alterações em domínios cognitivos, que interferem na capacidade para lidar com dinheiro e no rendimento ocupacional, foram os sinais mais comumente relatados. Portanto, a percepção da maior parte dos cuidadores sobre o estado de saúde dos familiares estava associada ao desempenho das atividades instrumentais.

\section{Interpretações de origem sociocultural, histórica e/ou biológica para as alterações do familiar}

A partir das percepções dos primeiros sinais da síndrome demencial e das mudanças ocasionadas pela doença no familiar, os cuidadores tecem interpretações sobre essas alterações.

\section{Origem sociocultural e histórica}

Os cuidadores combinam os significados da demência com eventos de vida marcantes no interior de um contexto histórico e sociocultural específico, em suas considerações sobre a doença. Doze cuidadores apontam como justificativas para as alterações dos familiares as histórias de suas vidas, considerando os aspectos afetivos e/ou materiais e/ ou sociais. Seis deles consideram os aspectos das relações de afeto - a ausência do amor ou do casamento, ou as perdas amorosas, ou um comportamento inapropriado nas relações amorosas com o sexo oposto - como causas para a síndrome demencial.

... um amor talvez, meu pai morreu muito novo, um amor não-correspondido... um abandono, abandono de amor... então, eu acho que o amor, se nós não tivermos fé em Deus, o amor te leva à demência, a doenças tenebrosas. Isso no meu modo de pensar... é muito importante o amor. Quando o meu pai morreu, ela tinha uns 40 e poucos anos... meu pai faleceu, e ela perdeu o amor dele, depois ela teve uma outra pessoa na vida dela por 20 anos que a deixou... (Paula)

Considerando a história de vida dos pacientes nos seus aspectos materiais e sociais, o apego ao dinheiro e ao lar, a perda do trabalho considerado um ideal de vida ou o trabalho excessivo, a história de maternidade e o estresse da modernidade são relacionados como causas da doença dos pacientes pela maioria dos cuidadores. Essas interpretações de origem psicossocial remetem à idéia de que a síndrome demencial estaria de alguma forma sob o domínio do paciente, sendo, assim, sua "responsabilidade" estar ou não doente. Uma entrevistada fornece mais indícios que fortalecem o pensamento de que a demência pode ser determinada por características da personalidade e do temperamento do paciente e, assim, "controlada" a partir de mudanças de atitudes (“... ela era uma pessoa muito rancorosa... é isso que levou ela muito jovem à demência... minha mãe é assim uma pessoa difícil, italiana difícil, difícil até para os filhos... essa doença de mal de Alzheimer leva a pessoa a cada vez ficar pior quando a pessoa não tem humildade..." - Paula).

As idéias de causalidade da doença descritas pelos entrevistados do presente estudo assemelhamse com as associações construídas pelos cuidadores 
latinos para explicar as causas da doença expressas em estudo realizado por Hinton \& Levkoff ${ }^{19}$. Estes contam histórias que atribuem o início e curso da doença ao contexto de eventos traumáticos ao idoso. Para as famílias latinas, o início ou piora da demência foram associados a eventos traumáticos e experiências afetivas dolorosas (como, por exemplo, solidão). Os eventos traumáticos podem consistir na fragmentação da família, devido à migração, discriminação, negligência dos filhos, mortes trágicas, dificuldades econômicas e perda da devoção da família.

Estereótipos culturais do envelhecimento e problemas médicos coexistentes também parecem ter influenciado as noções dos cuidadores sobre a demência no presente estudo e estão de acordo com estudo realizado por Ikels $^{20}$. Este revela como um número de fatores, incluindo baixas expectativas em relação ao idoso com baixa escolaridade, estereótipos culturais do envelhecimento e problemas médicos coexistentes, levam à pequena valorização de sintomas, como a perda de memória em idosos de uma zona rural na China. No presente estudo, seis cuidadores consideram a possibilidade de os primeiros sinais observados da doença fazerem parte do envelhecimento normal, e cinco cuidadores associam as manifestações da doença aos distúrbios mentais pré-existentes ou coexistentes, ocasionando demora para a aquisição de uma maior consciência sobre a doença pelos entrevistados. Essas interpretações podem ajudar na compreensão do fato de os prejuízos mais leves de memória dos familiares não terem sido notados pelos mesmos.

... a gente custou muito para cair a ficha, a gente achava que era cabeça cansada, está caducando cedo... a gente pensava: 'quem sabe ela está caducando', mas a N. era mais atenta, e ela notou que ela estava doente... (Maria)

... quando ela veio de São Paulo há 20 anos, o estado dela estava bem crítico, mentalmente bem crítico... ela tem histórico de loucura na família, ela está com a mente muito perturbada mesmo... eu não sei o que leva uma pessoa a ter problema mental, porque é tanta gente que você conhece que, de repente, tem um problema mental, e você não sabe nem por que... (Ana)

\section{Origem biológica}

Embora a maior parte dos cuidadores considere a síndrome demencial como resultado de sofrimentos do passado, eles não desconhecem a natureza biológica e incurável da doença. Alguns cuidadores demonstram um conhecimento prévio da DA, mesmo antes do diagnóstico do médico. Esses casos mostram como a consciência sobre a doença sofre influência de mecanismos psicológicos (negação da doença) que, muitas vezes, podem dificultar uma maior percepção e ação em relação ao problema ("a gente estava percebendo: papai está com Alzheimer. Aí, se lê uma coisinha ali, uma informação aqui... não, não é Alzheimer não, deve ser coisa da idade mesmo, cansaço, depressão" - Célia). Somente três cuidadores - duas com ensino médio completo, sendo que uma é técnica em enfermagem, e um com nível universitário - interpretaram as modificações do familiar apenas como conseqüência das alterações no cérebro provocadas pela doença, desconsiderando causas psicossociais.

Porque, no Mal de Alzheimer, o cérebro vai definhando, ele vai reduzindo mesmo, não é isso? Os neurônios vão se perdendo, vão se desgastando, então, não tem força para o pensamento, o raciocínio, a memorização... vão ficando cada dia mais fracos... (Clarice)

O conhecimento biomédico prévio sobre a doença, através dos meios de comunicação ou a partir da experiência de observar outro ente próximo da família com demência, parece ter influenciado nas considerações sobre as origens biológicas da doença e na possibilidade de perceber e reconhecer logo no início os sinais mais precoces da mesma.

Não foi nem eu que percebi, foi meu filho: 'pai, a mamãe está esquisita, não está notando, não? Você está vendo que ela não fala coisa com coisa, está assim meio avoada...'. Aí, eu estava com o carro ligado e ouvi uma reportagem entrevistando um médico da USP de São Paulo... e ele estava falando exatamente sobre o mal de Alzheimer, e tudo que ele falou naquela hora, ela se encaixou em todos os itens... (Antônio)

Elementos mentais, sociais, afetivos, históricos e cognitivos se articulam para mediar essas interpretações da realidade por parte dos entrevistados. Com o peso da tradição, da memória e do passado, esses cuidadores constroem uma realidade social que também recebe a influência dos meios de comunicação, das teorias, das informações do discurso biomédico e dos indivíduos com os quais interagem.

Ao mesmo tempo em que os cuidadores consideram eventos de vida, organicidade e hereditariedade para explicar o problema do familiar, levantam também outros aspectos que estão intimamente associados ao contexto sociocultural. 
A partir das entrevistas realizadas, é possível observar que, no início do processo de reconhecimento do problema, os cuidadores buscam diversas explicações para as manifestações da doença (“eu não sei se é um distúrbio mental, ou se é por causa da idade, ou se foi depois que ela levou um tombo, sabe, e bateu com a cabeça..." - Lara). A consciência da doença deve ser observada como produto da interação entre o processo psicossocial e o déficit cognitivo ${ }^{11}$. Farmer \& Good $^{21}$, em suas revisões sobre as representações da doença na antropologia médica, afirmam que as idéias sobre natureza e significados da doença freqüentemente ocorrem na forma de histórias situadas em um contexto sociocultural particular. A articulação entre os universos sociocultural e de experiência pessoal influencia as noções sobre saúde e doença relacionadas à demência.

As percepções e as interpretações dos entrevistados em relação às alterações decorrentes da síndrome demencial irão influenciar o momento do reconhecimento de que um problema acomete o seu familiar e, conseqüentemente, o processo de tomada de decisões.

\section{Reações do cuidador às alterações do familiar}

\section{Procura por ajuda médica}

A primeira reação da maioria dos entrevistados foi procurar ajuda médica após perceberem as manifestações do problema nos familiares. Alguns obstáculos para a concretização dessa ação foram relatados pelos cuidadores: demora em conseguir atendimento médico, falta de tempo da família para conciliar as idas aos serviços de saúde com suas ocupações e resistência do próprio paciente em ir ao médico.

... minha irmã notou que ela estava doente, começou a fazer uns tratamentos com ela, mas demorou para o médico do posto também descobrir que ela podia ter essa doença... Eu não sabia que ela tinha essa doença, a gente só sabia que ela não estava bem. Que alguma coisa tinha... ai que a $N$. dentro das limitações dela também porque ela trabalha o dia inteiro, começou a marcar médico, a levar... você sabe como que é essas coisas, tudo demorado e ela sem tempo, e a gente sem entender.. (Maria)

No caso de três cuidadoras - com ensino fundamental completo e incompleto e universitário -, não foram as manifestações da síndrome demencial que impulsionaram a procura pela ajuda médica, mas sim os sinais de problemas físicos de outras naturezas. Nos pacientes cuidados por essas três entrevistadas, o diagnóstico da síndrome demencial foi realizado como conseqüência de uma avaliação mais global da equipe de saúde, e não como resultado de uma demanda específica relacionada à demência pelo cuidador. As associações entre as manifestações dos pacientes e outros transtornos mentais e/ou perda de memória como parte do envelhecimento normal parecem estar relacionadas com as reações de procurar os serviços médicos devido aos problemas físicos, e não mentais. Aquelas três cuidadoras confundem os sinais da demência com problemas psiquiátricos co-existentes ou préexistentes, retardando a aquisição da consciência da doença e a procura pela ajuda médica ("ela sempre foi cabeça fraca" - Joana; "eu não sei se é um distúrbio mental ou se é por causa da idade" - Lara; "ela tem histórico de loucura na família... ela está com a mente muito perturbada mesmo" - Ana). Já os três entrevistados que consideravam somente as origens biológicas para explicar a doença tiveram uma maior prontidão para ação em relação à procura pelos serviços de saúde.

... ele estava esquecendo muito, se perdendo na rua... a supervisora do asilo onde a irmã dele está reparou que ele estava muito aéreo... uma vez ele foi ao banco e bloqueou a própria conta porque esqueceu a senha... procurei o médico imediatamente... eu já sabia que era esse problema, porque as irmãs dele já tinham tido... uma morreu há 1 ano... (Vilma)

Não somente as interpretações com origens psicossociais e/ou biológicas interferem nas reações dos cuidadores, mas também o impacto das manifestações da demência nestes. Estudo realizado por Hinton \& Levkoff ${ }^{19}$ mostra como a perda de identidade e "perda de si mesmo" são signos identificados, a partir das narrativas de cuidadores de diversas etnias, que não fazem parte dos critérios diagnósticos para demência. "A perda de si mesmo" simultaneamente expressa e constrói sentimentos de pena e tristeza em parte da família e representa um significado da demência formado culturalmente que atravessa as barreiras étnicas. No presente estudo, os cuidadores não se utilizam desse termo para denominar as alterações decorrentes da demência, porém a maioria deles reconhece o problema quando seus familiares começam a perder as habilidades que os identificavam como indivíduos, tendo como resposta inicial a procura pela assistência de saúde. Sintomas comportamentais como agressividade, agitação principalmente à noite e comportamento de 
fuga também influenciaram na busca pela ajuda médica (“... tem dia que ela fala que quer ir embora, que vai embora, um dos motivos da gente ter levado na psiquiatra foi esse... ela querer fugir toda hora" Ana).

\section{Responsabilização pelo cuidado afetivo e material}

Além da procura pelo suporte médico, os cuidadores com maior renda contrataram cuidadores formais ou pessoas sem conhecimento técnico para auxiliá-los no cuidado ao paciente. Todos os entrevistados relatam atitudes que buscam tornar o contato com o familiar o mais próximo possível e fornecer o cuidado de forma afetiva. Para isso, os cuidadores levam seus parentes para sua própria casa ou saem de seu lar para passar dia e noite com os mesmos em suas residências, valorizando o contato afetivo como ponto essencial do suporte ao idoso.

Nessas alturas, eu já a trouxe para morar aqui em casa, pois ela já estava bem doente, minha mãe também adoeceu, minha irmã trabalhava o dia inteiro, como trabalha até hoje, então eu tenho que levar ela para perto para eu acompanhar, há uns 12 anos... Foi acolher mesmo, cuidar. Eu mesmo tomei a providência de trazer ela para minha casa... nossa reação foi de cuidar dela com muito carinho, muita atenção, muito amor... mas sem sabedoria, sem aquela facilidade, sem profissionalismo mesmo. (Maria)

As ações são definidas pelo modo como os cuidadores interpretam a situação que vivenciam. Como já explicitado anteriormente, a maior parte dos entrevistados detiveram-se nas dimensões psicossociais para explicar as causas da demência, sendo as dimensões fisiológicas, genéticas e de hereditariedade também abordadas, mas com menos freqüência pelos mesmos. Essa consideração pode ajudar na compreensão do contraste entre o atual estudo e os achados de pesquisa qualitativa com cuidadores principais de um grupo de suporte aos familiares de pacientes com demência e alto nível de dependência, realizada no Rio de Janeiro ${ }^{22}$. Nesse estudo, os sujeitos enfocaram as causas biológicas da doença e se interessaram por todas as informações que pudessem explicar o quadro patológico. Segundo comentário dos próprios autores, essa característica pode ser conseqüência do contexto do grupo e da coordenação deste por profissionais de saúde, que, no imaginário dos cuidadores, têm conhecimentos referentes à origem da doença. Para os cuidadores dessa pesquisa, o cuidado técnico de um cuidador formal é mais importante do que o contato afetivo proporcionado pelo próprio familiar, ao contrário do observado na presente pesquisa.

Porém, no presente estudo, mesmo aqueles cuidadores que desconsideram as origens psicossociais da doença, levando em conta somente a origem biológica, colocam como importante para o cuidado "o carinho e a paciência". Seria simplismo associar somente as interpretações sobre a origem biológica da doença ao cuidado técnico, com menor ênfase no aspecto afetivo. A relação afetiva entre paciente e cuidador, o estado afetivo do cuidador e suas características pessoais irão influenciar o processo de cuidado. Como exemplo, pode-se citar o caso do único cuidador do sexo masculino com 75 anos, dois filhos adultos e que, apesar de considerar somente a origem biológica da doença, cuida de sua esposa com demência em fase moderada há 5 anos, sem ajuda de qualquer cuidador formal ou outro membro da família. Embora tenha renda (mais de 20 salários mínimos) própria para a contratação desse profissional, assume os cuidados da esposa e da casa, sugerindo uma dificuldade em distinguir o que é ser um cuidador de sua condição de marido.

Informações prévias e as noções biomédicas sobre a demência adquiridas durante o processo de cuidado fornecem subsídios aos cuidadores na interpretação dos fenômenos observados no familiar, influenciando, assim, suas reações diante do problema e os arranjos intrafamiliares. As origens psicossociais para a doença se articulam com os conhecimentos biomédicos, favorecendo o paciente, que recebe um cuidado que, além de afetivo, leva em consideração suas necessidades biológicas e se adapta às suas transformações físicas secundárias à demência (“... enquanto ela tiver um suspiro, eu não vou abandonar ela, porque foi o abandono que colocou ela nesse estado..." - Paula; "Tudo que eu ouço falar que é bom, eu faço. Ela estava engasgando muito, aí eu a levei no geriatra, e ela indicou uma fonoaudióloga, aí não passou e eu aí procurei uma nutricionista... e o mais interessante são as fases, naquela época do engasgo eu ficava louca" - Luiza).

\section{Considerações finais}

Como afirma $\mathrm{Schutz}^{23}$, cada ator social experimenta e conhece o fato social de forma peculiar. É a constelação das diferentes informações individuais vivenciadas em comum por um grupo que permite compor o quadro global das estruturas e das relações, onde o mais importante não é a soma dos elementos, mas a compreensão dos modelos culturais e da particularidade das determinações. 
Os resultados da pesquisa mostram que a síndrome demencial não é detectada de forma precoce pelos cuidadores que percebem os sinais do problema, principalmente quando o familiar tem suas habilidades instrumentais prejudicadas pela doença. As dimensões fisiológicas, genéticas e de hereditariedade foram abordadas pelos cuidadores, mas com menos freqüência, para explicar as causas da demência. A maior parte dos entrevistados detevese nas dimensões psicossociais e socioculturais. Essas diferentes interpretações repercutem na aquisição da consciência da doença e, conseqüentemente, nas atitudes diante do problema. Mecanismos psicológicos (negação da doença) e idéias sobre as manifestações da doença associados aos estereótipos sobre o envelhecimento ou aos problemas médicos pré-existentes ou co-existentes retardaram a obtenção do conhecimento sobre a demência e a procura pelo tratamento médico. Apesar de a maioria dos entrevistados ter consciência da natureza biológica da doença, no momento da entrevista, ainda assim, eles teciam interpretações de causalidade entre a história de vida do paciente e a demência, o que remete à idéia de que as alterações secundárias à síndrome demencial poderiam ser evitadas ou controladas pelos pacientes. Compreender melhor a doença dá mais segurança e senso de controle para o cuidador. Ter uma explicação lógica para as manifestações apresentadas pelo paciente conforta o cuidador, pois permite que ele perceba que a doença não tem nada a ver com o relacionamento dele com a pessoa cuidada ou que os sintomas comportamentais da demência não são dirigidos propositadamente a ele. Proporciona, ainda, a possibilidade de um tratamento para o doente, e conseqüentemente, apoio e orientações aos cuidadores durante o processo de cuidado.

É importante considerar, porém, os limites da análise do presente estudo inerente ao próprio desenho da metodologia qualitativa e à prática científica das ciências sociais. Por exemplo: (a) a presente análise elege um determinado escopo teórico como marco orientador, o que conduz às análises que valorizam determinados aspectos da realidade em detrimento de outros (limites teóricos); (b) impossibilita uma generalização direta ao universo macro, sendo necessárias mediações e comparações; (c) atribui uma demarcada relevância aos processos interpretativos na relação pesquisador/sujeitos pesquisados, o que exige uma contínua vigilância epidemiológica; (d) torna inadequada a predição do comportamento futuro da realidade estudada com base na simples análise de variáveis, uma vez que diz respeito à ação histórica dos sujeitos, permitindo apenas a avaliação de prováveis cenários de permanência e/ou transformação/mudança dessas relações ${ }^{24,25}$. Apesar das limitações, a pesquisa qualitativa é imprescindível quando se quer trazer à tona a compreensão dos fenômenos saúde e doença a partir dos valores, atitudes e crenças dos grupos a quem a ação se dirige. Este estudo demonstra que são necessários maiores esclarecimentos quanto aos sinais e sintomas da demência à população - sempre considerando o contexto sociocultural e econômico daqueles para os quais as informações se destinam - para que o reconhecimento da doença possa ser realizado mais prontamente pelos familiares do idoso. Programas de formação e educação permanente voltados para os profissionais de saúde que trabalham na atenção básica do Sistema Único de Saúde, na área de saúde da pessoa idosa, deveriam ser desenvolvidos de forma cada vez mais crescente. Isso permitiria um aprimoramento no diagnóstico precoce da síndrome demencial, a investigação de causas potencialmente tratáveis e o tratamento adequado dos pacientes com demências irreversíveis, trazendo conseqüências positivas para os cuidadores principais e outros membros da família. Esses teriam suporte para lidar com as manifestações comportamentais e psicológicas da doença e esclarecimentos quanto aos cuidados básicos (alimentação, higiene), atenuando as dificuldades surgidas durante o processo de cuidado.

\section{Referências}

1. Carvalho JA, Garcia RA. O envelhecimento da população brasileira: um enfoque demográfico. Cad Saude Publica. 2003;19:725-33.

2. American Psychiatric Association. Diagnostic and statistical manual of mental disorders (DSM IV). 4th ed. Washington: APA; 1994

3. Jorm AF. The epidemiology of Alzheimer disease and related disorders. London: Chapman Hill; 1990.

4. Jorm AF, Korten AE, Henderson AS. The prevalence of dementia: a quantitative integration of the literature. Acta Psychiatr Scand. 1987;76:465-79.

5. Herrera Junnior RE, Caramelli P, Nitrini R. Estudo epidemiológico populacional de demência na cidade de Catanduva: estado de São Paulo, Brasil. Rev Psiquiatr Clin. 1998;25:70-3.

6. Cohen CA, Gold DP, Shulman KI, Wortley JT, McDonald G, Wargon M. Factors determining the decision to institutionalize dementing individuals: a prospective study. Gerontologist. 1993;33:714-20.

7. Coen RF, Swanwick GRJ, O'Boyle CA, Coakley D. Behaviour disturbance and others predictors of carer burden in Alzheimer's disease. International J Geriatr Psychiatry. 1997;12:331-6.

8. Haley WE. The family caregiver's role in Alzheimer's disease. Neurology. 1997;48 Suppl 6:S25-9.

9. Levesque L, Ducharme F, Lachance L. Is there a difference between family caregiving of institutionalized elders with or without dementia. West J Nurs Res. 1999;21:472-97.

10. Giacomin K, Uchôa E, Firmo JOA, Lima-Costa MF. Projeto Bambuí: um estudo de base populacional da prevalência e dos fatores associados à necessidade de cuidador entre idosos. Cad Saude Publica. 2005;21:80-91. 
11. Clare L. Managing threats to self: awareness in early stage Alzheimer's disease. Soc Sci Med. 2003;57:1017-29.

12. Dourado M. Psicoterapia de paciente com demência. In: Bottino CM, Laks J, Blay SL. Demência e transtornos cognitivos em idosos. Rio de Janeiro: Guanabara Koogan; 2006. p. 363-70.

13. Poveda AM. An anthropological perspective of Alzheimer disease. Geriatr Nurs. 2003:24:26-31.

14. Spink MJP. O conceito de representação social na abordagem psicossocial. Cad Saude Publica. 1993;9:300-8.

15. Spink MJP. Desenvolvendo as teorias implícitas: uma metodologia de análise das representações sociais. In: Guareschi PA, Jovchelovitch S, organizadores. Textos em representações sociais. 7. ed. Petrópolis: Vozes; 2002. p. 117-45.

16. Oliveira RD, Oliveira MD. Pesquisa social e ação educativa: conhecer a realidade para poder transformá-la. In: Brandão CR, org. Pesquisa participante. 6. ed. São Paulo: Brasiliense. 1986. p. 17-33.

17. Bardin L. Análise de conteúdo. Lisboa: Edições 70; 1977.

18. Sthal SM. Ampliadores cognitivos. In: Sthal SM. Psicofarmacologia: base neurocientífica e aplicações práticas. Rio de Janeiro: Médica e Científica; 2002. p. 449-88.

19. Hinton WL, Levkoff. Constructing Alzheimer's: narratives of lost identities, confusion and loneliness in old age. Cult Med Psychiatry. 1999;23:453-75.

20. Ikels C. Becoming a human being in theory and in practice: chinese views of human development. In: Kertzer D, Schaie KW, editors. Social structure and aging: comparative perspectives on age structuring in modern societies. Hillsdale: Erlbaum; 1989. p. 109-134.

21. Farmer P, Good BJ. Illness Representations in medical anthropology: a critical review and a case study of the representation of AIDS in Haiti. In: Skelton JA, Croyle RT, editors. Mental representation in health and illness. New York: Springer-Verlag; 1991. p. 132-62.

22. Silveira TM, Caldas CP, Carneiro TF. Cuidando de idosos altamente dependentes na comunidade: um estudo sobre cuidadores familiares principais. Cad Saude Publica. 2006;22(8):1629-38.

23. Schutz A. Equality and the social meaning structure. Collected Papers II. Hague: Martinus Nijhoff; 1964.

24. Patton MQ. How to use qualitative methods in evaluation. London: Sage; 1998.

25. Deslauriers JP, director. Les méthodes de la recherche qualitative. Québec: Presses de I' Université du Quebec; 1987. 